\title{
PAPEL DE LA ECOGRAFÍA TRANSRECTAL EN CRIOTERAPIA Y BRAQUITERAPIA PROSTÁTICAS.
}

\author{
Fernando Arias Fúnez, Ángel Escudero Barrilero, Rafael Rodríguez-Patrón Rodríguez y \\ Carmen Vallejo Ocañal.
}

Servicio de Urología. Servicio de Oncología Radioterápica'. Hospital Ramón y Cajal. Madrid. España.

\begin{abstract}
Resumen.- OBJETIVO La ecografía transrectal es el método que proporciona una imagen directa de la próstata, sus límites, alteraciones estructurales y morfológicas y relaciones anatómicas. El volumen prostático es, en consecuencia, fácil de determinar, siendo el primer paso necesario para la aplicación de determinados procedimientos terapéuticos.
\end{abstract}

La crioterapia y la braquiterapia prostáticas se han desarrollado en los últimos años como opciones mínimamente invasivas para el tratamiento del cáncer de próstata. La ecografía transrectal de próstata ha permitido la aplicación de estas tecnologías en la práctica diaria garantizando altos índices de eficacia y seguridad.

La criocirugía es la congelación controlada de los tejidos. La ecografía transrectal de próstata es el único método capaz de reflejar en tiempo real la evolución de la crioablación prostática, permitiendo al urólogo controlar la evolución de la bola de hielo y alcanzar las estructuras anatómicas deseadas garantizando los objetivos oncológicos y disminuyendo la aparición de complicaciones y secuelas.

La braquiterapia como forma de radioterapia local intraprostática necesita de cálculos volumétricos y dosimétricos exactos previos a la implantación de la fuente radioactiva en el interior de la glándula. Con ecografía transrectal de próstata se realizan cortes ecotomográficos para el cálculo del volumen y planimetría prostáticos. Una vez realizada la dosimetría y para realizar el implante de las agujas cargadas con las semillas en su lugar exacto es necesario el control con ecografía transrectal en tiempo real.

Hoy en día la crioterapia y braquiterapia prostáticas serían inconcebibles sin la ecografía transrectal.

Palabras clave: Ecografía transrectal. Crioterapia. Braquiterapia. Ecografía urológica.

Summary.- OBJECTIVES: Transrectal ultrasound is the method that gives a direct image of the prostate, its limits, structural and morphologic anomalies, and anatomical relations. Therefore, prostate volume is easily determined, being the first step for the application of certain therapeutic procedures.

Prostatic cryotherapy and brachytherapy have been developed over the last years as minimally invasive options for the treatment of prostate cancer. Transrectal ultrasound of the prostate has allowed the application of these technologies in the daily practice, guaranteeing high efficacy and saferty indexes. 
Cryosurgery is the controlled freezing of tissues. Prostatic transrectal ultrasound is the only method able to show the real-time evolution of prostatic cryoablation, allowing the urologist to control the evolution of the ice ball and to reach the targeted anatomical structures guaranteeing the oncological objectives, and diminishing complications and sequels.

Brachytherapy, as a local intraprostatic radiotherapy, needs exact volume and dose calculations before the implant of the radioactive source within the gland. With transrectal ultrasound of the prostate, ultrasound-tomographic cuts are made for prostatic volume calculation and planimetry. Once dosimetry is completed, real-time transrectal ultrasound control is necessary to perform the implant of the needles loaded with the seeds.

Today, prostate cryotherapy and brachytherapy would be inconceivable without transrectal ultrasound.

Keywords: Transrectal ultrasound. Cryotherapy. Brachytherapy. Urological ultrasound.

\section{INTRODUCCIÓN}

Es evidente que el desarrollo de la ecografía ha supuesto una elevada rentabilidad diagnóstica en la mayoría de las enfermedades del tracto genitourinario y en concreto en el estudio de la próstata, objeto de una patología muy frecuente.

Aunque la ecografía abdominal permite identificar la mayoría de las alteraciones morfológicas inducidas por el crecimiento benigno de la glándula prostática, ve limitada su utilidad para valorar las alteraciones estructurales. Su escasa resolución, la utilización de frecuencias bajas y la localización profunda de la glándula en el espacio pelviano son responsables de estas limitaciones.

La introducción de la vía endorectal para la exploración ecográfica ha proporcionado una mejora indiscutible en la calidad y precisión de las imágenes obtenidas, permitiendo mostrar cambios parenquimatosos más sutiles, delimitar en mayor medida los límites de la glándula y el alcance de las lesiones, lo que supone un avance importante en el campo de la patología tumoral de la próstata. Podemos afirmar que la ecografía transrectal es el método que permite obtener una imagen directa de la glándula.

Si es indiscutible que el desarrollo de la ecografía transrectal ha supuesto una mejora importante en el diagnóstico de la patología prostática, no de- bemos olvidar las implicaciones que en el campo terapéutico supone tener, como ya hemos comentado, una imagen más nítida, perfectamente delimitable y directa de la próstata.

La primera consecuencia derivada de esta mejora es poder calcular de una forma más exacta el volumen de la glándula prostática aplicando modelos matemáticos más o menos complejos, o aproximaciones prácticas, o mediante cortes ecotomográficos, con las implicaciones terapéuticas que de ello se derivan. En la crioterapia y braquiterapia objeto de este análisis, el cálculo del volumen prostático siempre es el primer paso en la aplicación de cualquiera de ellas, utilizando la metodología más adecuada en función del tratamiento a realizar.

Para tratar la patología prostática tumoral se han venido desarrollando en los últimos años diversos procedimientos terapéuticos encaminados a complementar a la prostatectomía radical como tratamientos primarios del cáncer de próstata en función de las características del paciente y del propio tumor.

Por otro lado, la urología también se encuentra inmersa en las corrientes actuales que buscan procedimientos mínimamente invasivos y que aseguren unos niveles de eficacia similares a los ofrecidos por las terapias ya estandarizadas. Es en este campo donde la ecografía transrectal de próstata representa un papel insustituible e imprescindible en el desarrollo y utilización de estas nuevas formas de tratamiento.

El objetivo de esta revisión es analizar el papel que la ecografía prostática por vía transrectal juega en la aplicación de la crioterapia y de la braquiterapia como técnicas mínimamente invasivas para tratar el cáncer de próstata. Hoy en día sería impensable la existencia de cualquiera de ellas sin el concurso de la ecografía transrectal.

\section{VOLUMEN PROSTÁTICO}

Tanto la crioterapia como la braquiterapia para el tratamiento del cáncer de próstata ven limitadas sus indicaciones en función del tamaño de la glándula. Está establecido que volúmenes superiores a los 45-50 cc son una contraindicación para la aplicación de cualquiera de las dos técnicas, siendo necesaria, en su caso, la aplicación de un tratamiento previo hormonal con objeto de reducir su tamaño. Como hemos referido anteriormente la ecografía transrectal es el mejor método para obtener el volumen prostático. Para ello, y de forma inicial, nosotros utilizamos las consideraciones de Terris (1) que 
asimila la fórmula del esferoide para el cálculo del volumen prostático:

"multiplicando el diámetro anteroposterior por el diámetro transverso elevado al cuadrado y por 0,52 ".

También, y de forma práctica en próstatas con volúmenes inferiores a los $60 \mathrm{cc}$, podemos seguir las recomendaciones de Monseur (2) utilizando los tres diámetros prostáticos (Figura $1 \mathrm{~A}$ y $1 \mathrm{~B}$ ):

"D1 x D2 x D3 / 3".

En la braquiterapia prostática se intenta un cálculo mucho más exacto durante el desarrollo de la técnica, realizando cortes ecotomográficos cada 5 $\mathrm{mm}$ desde la base al ápex prostático, como veremos más adelante al describir con detalle las implicaciones de la ecografía transrectal en la braquiterapia prostática, aunque en la valoración y selección inicial de los pacientes utilicemos la aproximación volumétrica referida.

\section{CRIOTERAPIA PROSTÁTICA}

La criocirugía se define como la congelación y destrucción de los tejidos "in situ". Desde que Gonder y cols. (3) en 1964 demostraran que el tejido prostático del perro se podía destruir por medio de la congelación, han sido varios los intentos de aplicación de este procedimiento a la glándula prostática humana teniendo en cuenta dos premisas: eliminar la totalidad del tejido glandular destruyendo por completo el tumor, y asegurar un mínimo de complicaciones salvaguardando las estructuras vecinas (cuello, esfínter estriado y recto) y preservando la mucosa uretral. Este mismo autor (4) aplicaba el nitrógeno

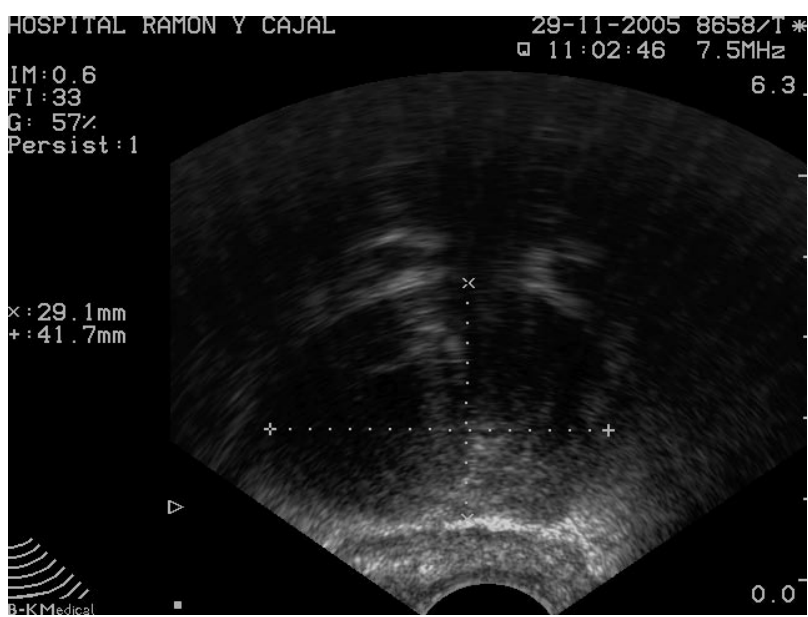

FIGURA 1Al Corte transversal. Diámetros D 1 y D2. líquido por vía transuretral y el control lo realizaba mediante tacto rectal. Evidentemente el número de complicaciones era alto derivado de la colocación imprecisa de la sonda y el precario control del enfriamiento.

Posteriormente el control de la bola de hielo se realizaba por vía perineal abierta, visualizando su evolución y protegiendo el recto con calor aplicado de forma local. De la misma forma se pretendía controlar la evolución del hielo y su progresión hacia el cuello vesical mediante visualización endoscópica suprapúbica.

Según progresaba la técnica y en un intento de alcanzar el tejido glandular periférico, la criosonda se introducía por vía percutánea perineal, pero el control seguía siendo mediante tacto rectal (5).

Todos estos sistemas introducidos en los años 60 se abandonaron por el alto índice de complicaciones, por otra parte inaceptables, derivados de la imprecisión a la hora de situar la criosonda y del mal control de la evolución del hielo en el tejido prostático.

Durante la década de los 80 se perfecciona la ecografía considerablemente y en 1988 Onik y cols. (6) utilizan la monitorización del proceso de congelación con ultrasonidos, por vía transrectal, y en tiempo real. La experimentación se hace en perros y se controla la colocación exacta de las criosondas y la regulación de la aplicación del frío. El procedimiento es completamente cerrado. Esta evolución permite a estos mismos autores introducir la técnica con éxito en la clínica (7) y moverse dentro de los márgenes establecidos por las premisas anteriormente señaladas de eficacia y seguridad.

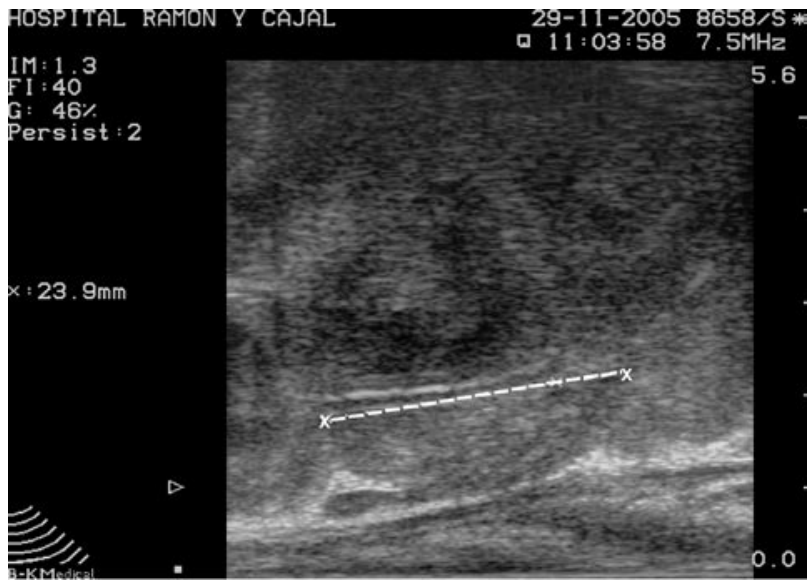

FIGURA IB) Corte longitudinal. Diámetro D3. 


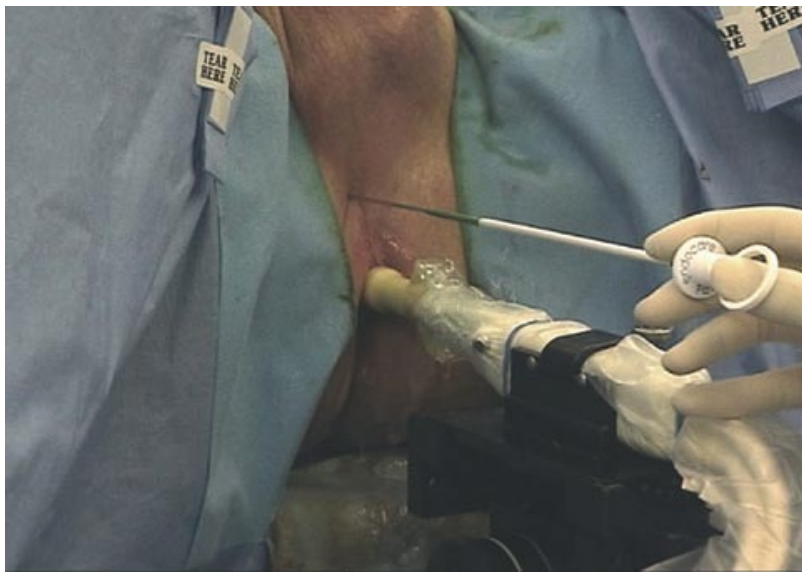

FIGURA 2. Imagen donde se aprecia el acceso percutáneo de la $7^{\underline{a}}$ criosonda

La progresión tecnológica permitió determinar la temperatura alcanzada mediante termosensores colocados estratégicamente. Wong y cols. (8) demuestran las ventajas de monitorizar la expansión de la bola de hielo con ecografía transrectal y la temperatura alcanzada mediante termosensores, colocados igualmente con control ecográfico transrectal, obteniendo resultados claramente superiores en cuanto a supervivencia libre de enfermedad.

En la actualidad la crioablación de la glándula prostática se muestra como una técnica emergente y eficaz para el tratamiento del adenocarcinoma de próstata con escaso riesgo quirúrgico y morbilidad baja (9). Es esencial durante todo el proceso que la calidad de la ecografía sea alta. Para ello es recomendable una sonda transrectal biplano, con una frecuencia de $7 \mathrm{Mhz}$, y que permita el paso fácil del corte transversal al longitudinal. El desarrollo de tecnología tridimensional ultrasónica nos ha permitido delimitar aún más la progresión de la bola de hielo en aquellas zonas donde la ecografía tradicional ve limitada su actuación (10). Como veremos más adelante la cara anterior de la glándula prostática permanece oculta durante la mayor parte del procedimiento.

El proceder técnico para la aplicación de los ciclos de congelación-calentamiento está totalmente estandarizado y su desarrollo ha sido posible gracias al concurso de la ecografía transrectal, visualizando la evolución del proceso en tiempo real.

El primer paso es la colocación precisa de las criosondas en el interior de la glándula prostática por vía percutánea perineal y dirigidas bajo control ecográfico transrectal biplano, (Figura 2).

Existe un preplaning ya estandarizado y aproximado de la colocación de las criosondas. Habitualmente utilizamos 6 aunque en ocasiones especiales, y en función de las características de la próstata se puede llegar a colocar hasta 8 criosondas:

- Anterolaterales (criosondas 1 y 2)

- Posterolaterales (criosondas 3 y 6 )

- Posteromediales (criosondas 4 y 5).

En la Figura 3A se presenta un corte esquemático de su colocación y la de los cinco termosensores: ápex, esfínter externo, fascia de Denonvilliers' o espacio próstato-rectal y bandeletas neurovasculares derecha e izquierda.

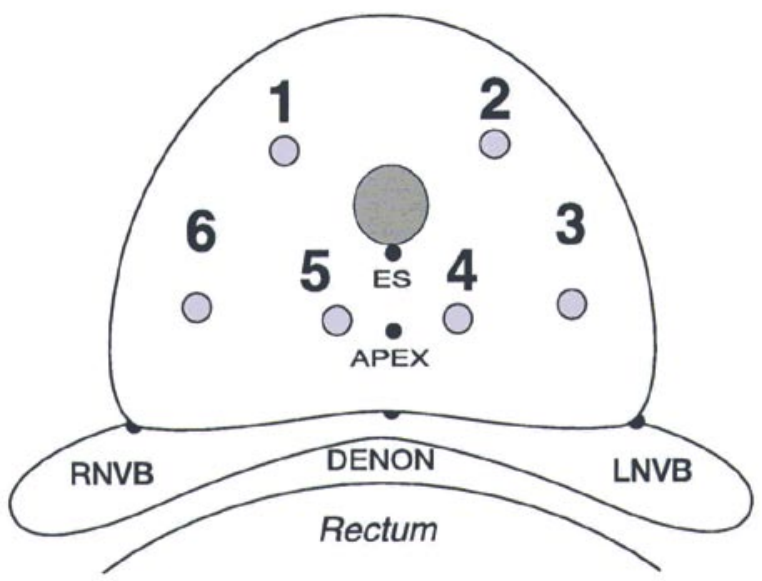

FIGURA 3A) Corte esquemático.

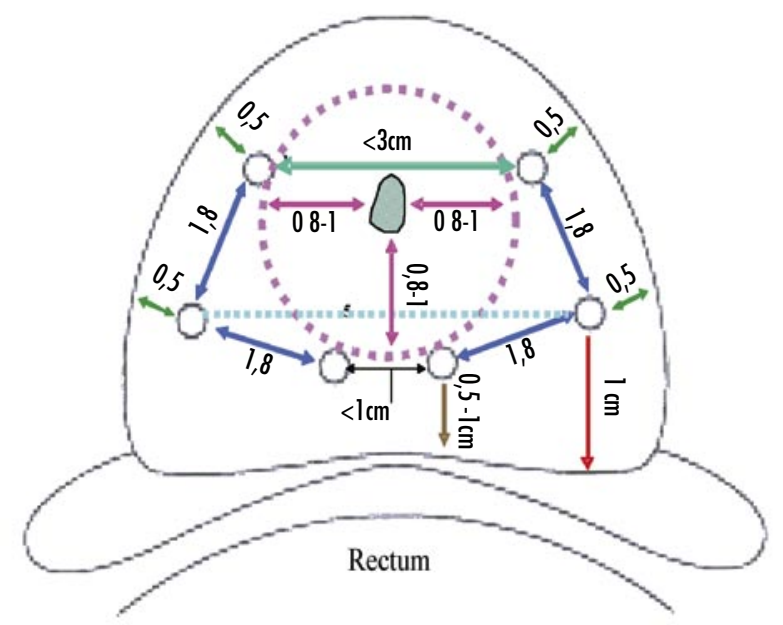

FIGURA 3B) Ubicación definitiva de las criosondas. 

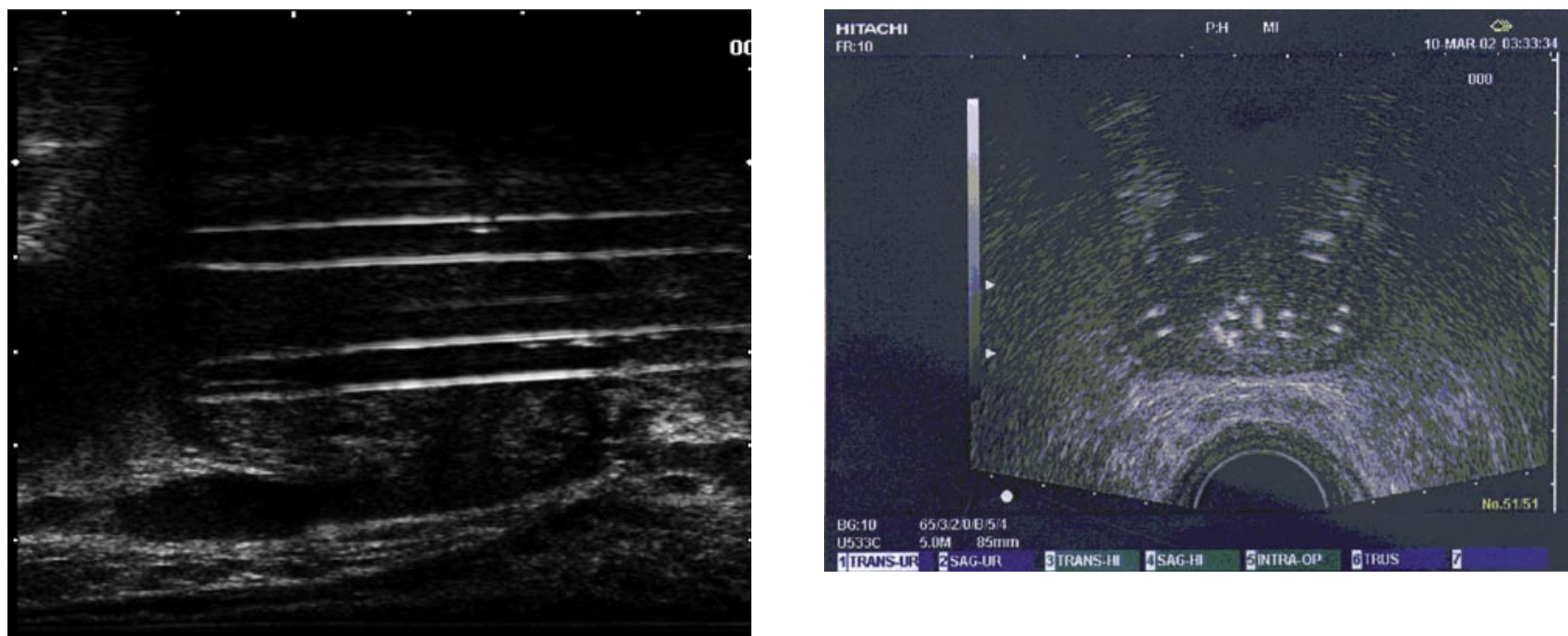

FIGURA 4. Corte longitudinal y transversal de la ubicación definitiva de las criosondas.

Y en la Figura 3B su planificación más o menos exacta en función de unas reglas que no son objeto de análisis en esta revisión, si bien es cierto que la ubicación definitiva dependerá de las características de la glándula y la proximidad del recto.

El control ecográfico transrectal es imprescindible en este punto. Debemos asegurar tanto la colocación exacta en el plano transversal como en el longitudinal, para asegurar que el crecimiento de la bola de hielo afectará e incluirá la totalidad de la glándula, especialmente su zona periférica. En la
Figura 4 podemos apreciar como, mediante ecografía en corte longitudinal, colocamos las criosondas con su extremo en relación con la base prostática, asegurando la congelación en toda la longitud de la próstata, y en corte transversal la ubicación espacial definitiva de las sondas para asegurar la inclusión de toda la zona periférica.

El segundo paso inicial es la colocación de los termosensores (Figura 5). Si bien es cierto que la colocación de las criosondas es fundamental, no lo
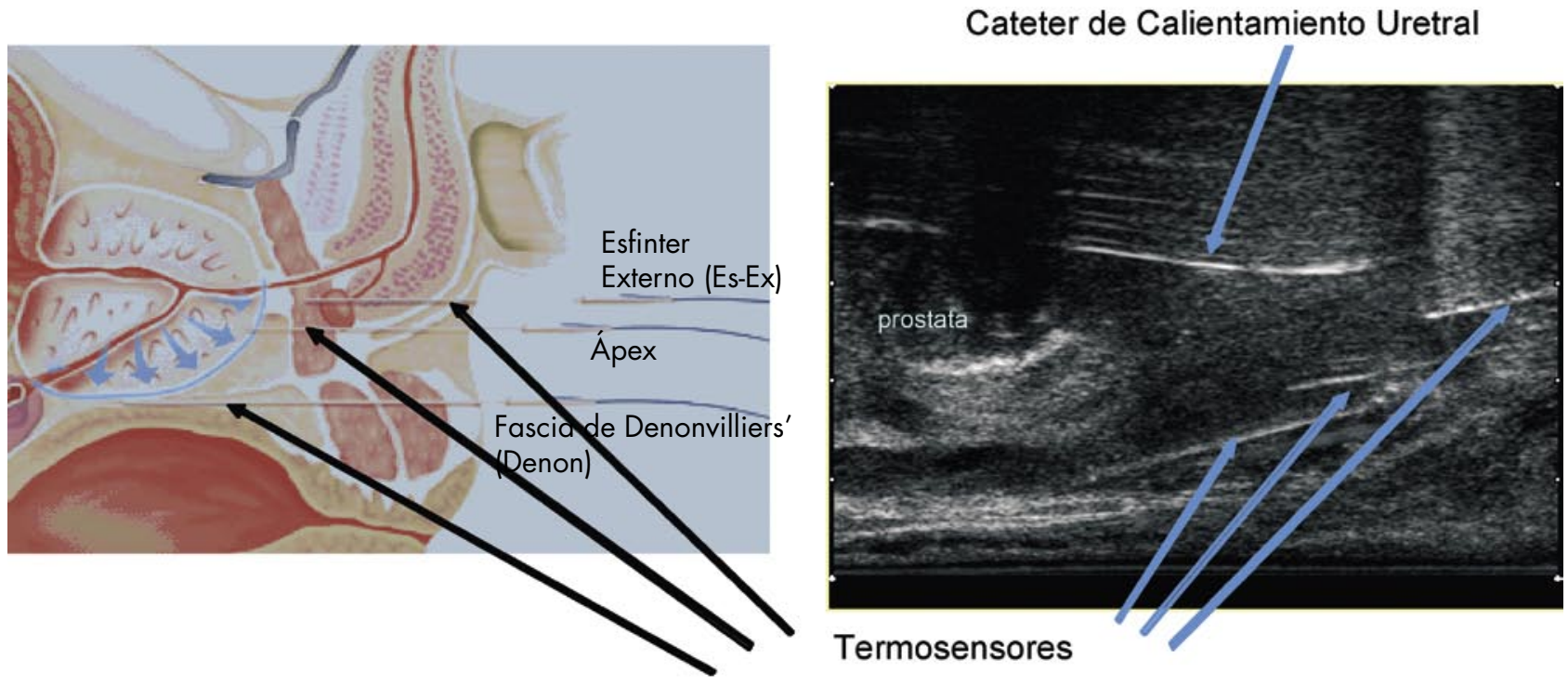

FIGURA 5. Esquema e imagen ecográfica de la ubicación de termosensores en ápex, esfínter y fascia Denonvilliers'. 
es menos el control de la temperatura alcanzada, tanto para asegurar el éxito de la técnica desde el punto de vista oncológico como para evitar la aparición de complicaciones no deseadas referidas al cuello vesical, el recto y al esfínter externo, puesto que no es posible diferenciar mediante ecografía transrectal hasta donde se extiende la bola de hielo con capacidad destructiva y deslindarla de las zonas más periféricas del área congelada donde no se alcanzan temperaturas lesivas útiles. Mediante ecografía transrectal en corte longitudinal colocamos termosensores en el esfínter externo, ápex, fascia de Denonvilliers' y mediante corte ecográfico transversal en ambas bandeletas neurovasculares. Evidentemente sin imagen ecográfica en tiempo real es imposible asegurar la correcta ubicación de estos termopares. De igual forma visualizamos la correcta colocación del sistema de calentamiento uretral que evita la congelación de la uretra prostática y la aparición de fístulas a ese nivel.

A partir de este punto comienza la crioablación prostática propiamente dicha. En un primer momento todas las criosondas se activan en posición de fijación ("stick", entre $-50^{\circ}$ y $-70^{\circ} \mathrm{C}$ ), formando un cilindro helado de pocos milímetros de espesor alrededor de toda la longitud operativa de la sonda. La imagen ecográfica que se traduce es de forma circular, de sombra ecográfica, sin ecos en su interior y con un refuerzo hiperecogénico en su periferia y proximal al transductor ultrasónico (Figura 6). Esta imagen se va a mantener durante todo el procedimiento, aumentando de forma progresiva en la medida que disminuye la temperatura al aplicar el frío y avanzamos en el procedimiento de la crioablación prostática.

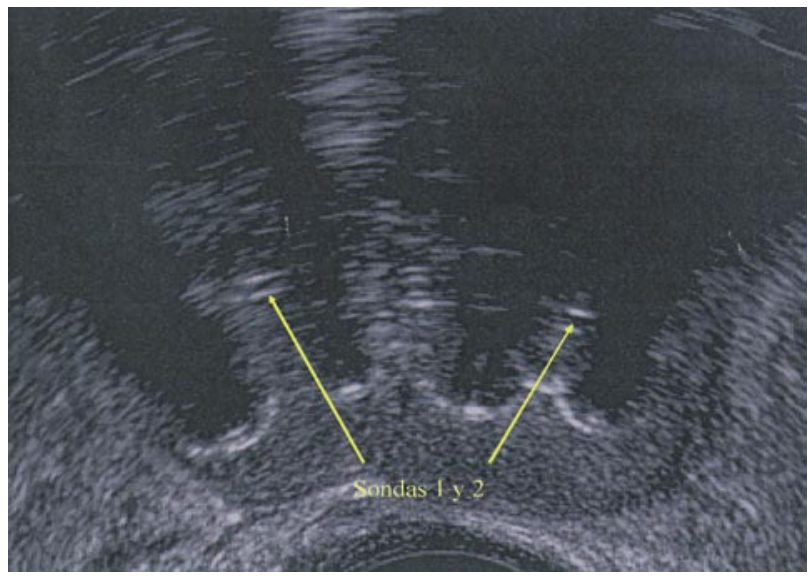

FIGURA 6. Todas las sondas se encuentran en fase de stick.
En la Figura 6 podemos apreciar, en corte transversal todas las sondas en fase de stick. Las bolas de hielo más próximas al transductor se definen perfectamente y dificultan la visión de las sondas anterolaterales (según el esquema, sondas 1 y 2). Asimismo podemos observar que el límite más anterior de la próstata se aprecia mal, perdiendo definición a medida que avanzamos en el proceso de congelación. Los últimos avances van encaminados a obtener imágenes tridimensionales que minimicen esta pérdida de visión (11).

En este momento y mediante corte longitudinal comprobaremos que la colocación de los termosensores es adecuada y no ha habido desplazamientos, especialmente en ápex y en esfínter externo.

La pérdida de visión del límite anterior de la glándula prostática no tiene grandes consecuencias, ni secuelas importantes. A ese nivel anatómico, los efectos descritos se refieren a la congelación de vasos venosos de la cara anterior prostática, plexo de Santorini y complejo de la vena dorsal del pene, que se traducen en un edema transitorio de cubiertas peneanas y tejido adiposo prepúbico, habitualmente sin mayores consecuencias.

Con objeto de esculpir una bola de hielo que se adapte lo más fielmente posible a la forma de la glándula prostática, la activación de las sondas se hace de forma progresiva. Iniciamos el procedimiento con las criosondas 1 y 2.

Con control ecográfico en corte transversal observamos la evolución de las bolas de hielo con la imagen hipoecóica característica y su refuerzo hiperecogénico periférico. No hay que olvidar que la imagen ecográfica es ligeramente mayor que la bola de tejido prostático congelado, hecho que hay que tener en cuenta a la hora de asegurar que el límite de congelación es el deseado. Es decir, nuestra imagen ecográfica del hielo debe superar el límite anatómico de la próstata al finalizar el tratamiento. En las Figuras 7A y 7B podemos apreciar la evolución del área congelada sobre las sondas activadas.

En la década de los 60 la técnica se abandonó por el alto índice de complicaciones. Una de las más temidas era la fístula rectal al alcanzar el frío la pared del recto. Fueron muchos los intentos para controlar y evitar esta complicación, pero hasta que no se utilizó la ecografía transrectal como medio de control, no se consiguió disminuir la incidencia de fístulas y reconsiderar la crioterapia como una técnica fiable y eficaz. 


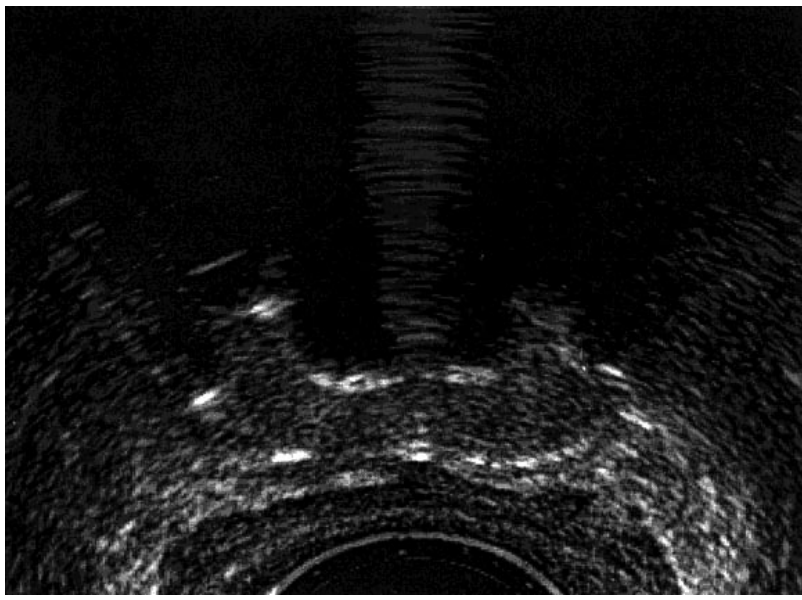

FIGURA 7A) Fases iniciales de la activación de las criosondas 1 y 2. Imagen transversal de la próstata en su tercio medio.

Con ecografía en corte transversal podemos delimitar perfectamente el recto y sus estructuras (mucosa, muscular y serosa), y de esta forma permitir que la bola de hielo crezca hasta alcanzar justo el límite con la pared rectal y poder afirmar que toda la cara posterior de la glándula prostática ha sido congelada. Pero la calidad de la imagen de la ecografía transrectal ha permitido ir aún más lejos. Con imagen longitudinal podemos inyectar suero salino fisiológico en el espacio virtual entre la pared del recto y la cara posterior de la próstata, incrementando la separación entre ambas hojas de la fascia de Denonvilliers'. Aunque el suero se va dispersando con el tiempo, sí nos permite incrementar el crecimiento de la bola de

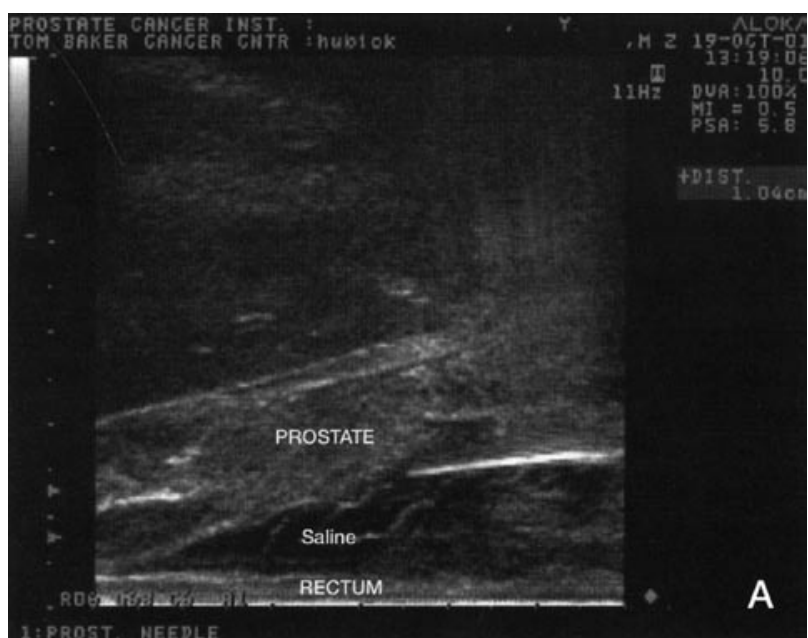

FIGURA 8A) Imagen longitudinal inyectando suero en el espacio próstato-rectal.

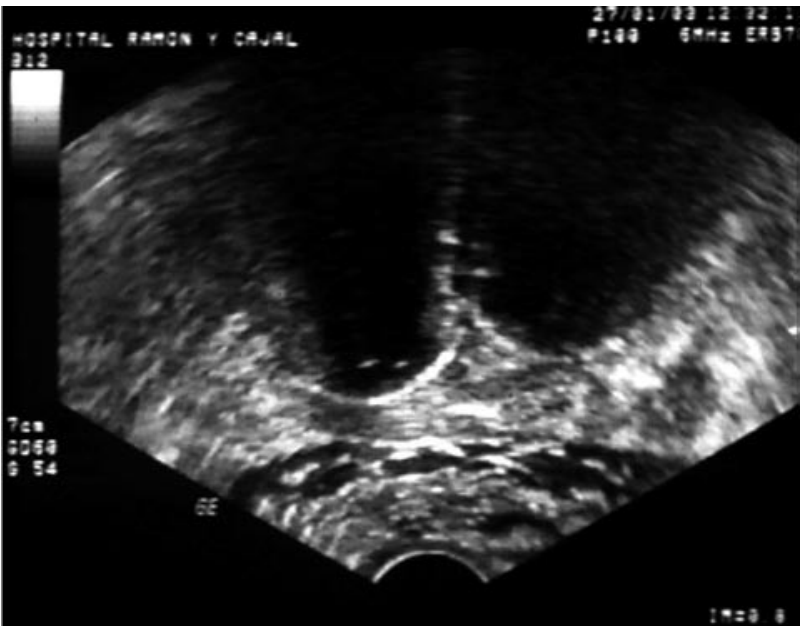

FIGURA 7B) La bola de hielo de las criosondas 1 y 2 va aumentando. Imagen transversal en la base prostática.

hielo y ser más agresivos disminuyendo claramente el índice de recidivas $(9,12)$. Este proceder se puede llevar a cabo antes de activar las sondas 1 y 2 o inmediatamente después, e incluso repetirlo en fases más adelantadas del procedimiento. En la Figura $8 \mathrm{~A}$ y $8 \mathrm{~B}$ podemos apreciar el espacio artificial creado a nivel de la fascia de Denonvilliers', que puede superar el centímetro de tamaño y proporcionar un gran margen de seguridad.

El procedimiento progresa activando sucesivamente las sondas 3 y 6 y por último las criosondas 4 y 5 . En las figuras siguientes (Figuras 9 a 12) apreciamos como podemos controlar con la ecografía

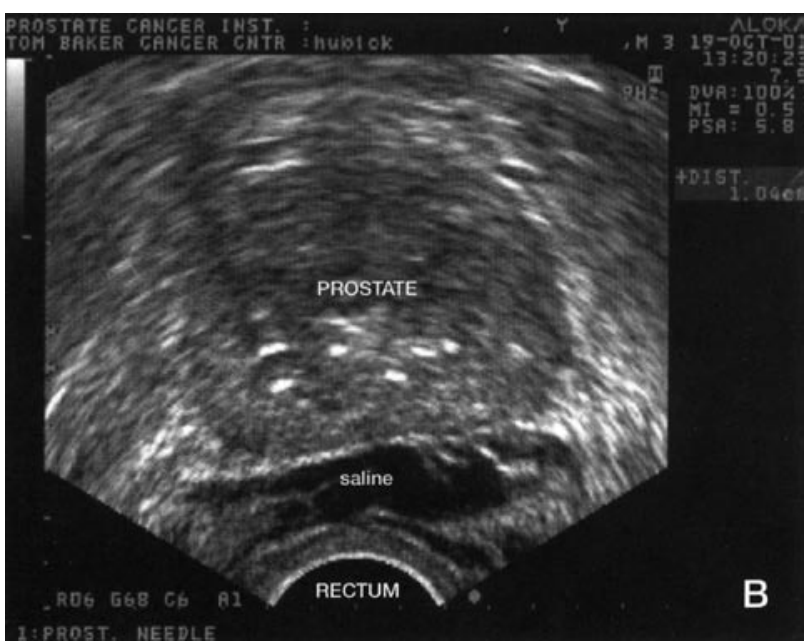

FIGURA 8B) Espacio artificial creado con suero salino entre recto y próstata. 


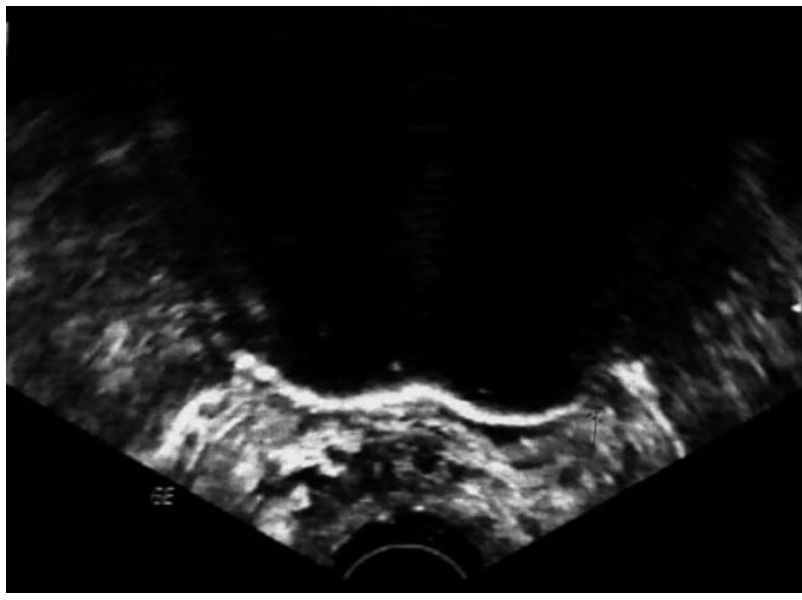

FIGURA 9. Progresión al activar sondas 3 y 6.

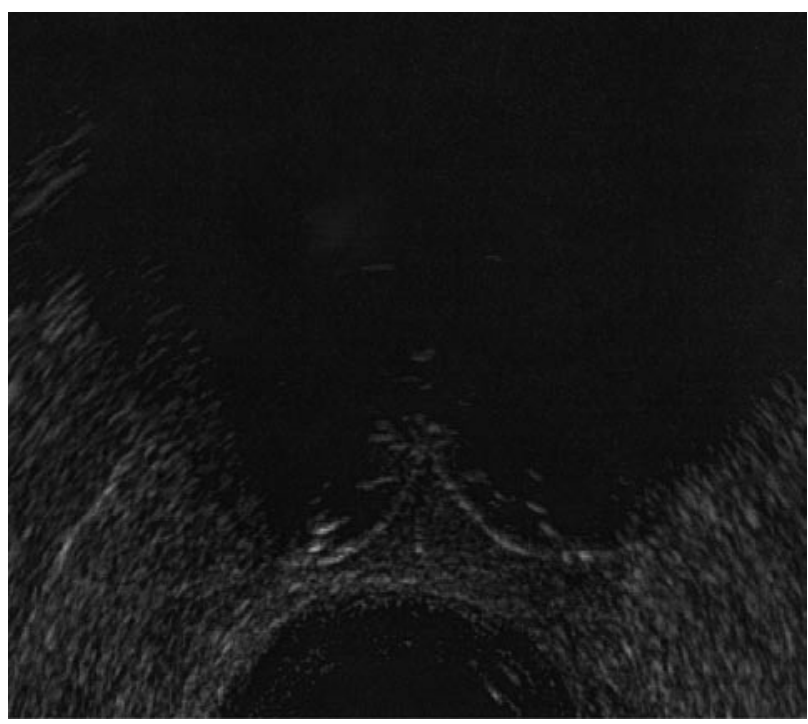

FIGURA 1 1. Activación de las sondas 4 y 5 /corte en ápex.

transrectal la bola de hielo y su velocidad de crecimiento y de esta forma aplicar las modificaciones necesarias (cambios en la intensidad y velocidad de enfriamiento) para alcanzar el fin deseado: la congelación total de la glándula prostática respetando los límites apropiados.

Al final del procedimiento toda la glándula se encuentra sustituida por una gran bola de hielo. Los límites prostáticos no son visibles, especialmente la cara anterior. Recordemos que los límites ecográficos de la bola helada deben ser mayores que los límites anatómicos de la glándula prostática. En este punto hay autores que introducen de nuevo suero salino en el espacio de Denonvilliers' con objeto de aumentar la agresividad de la técnica justo antes de finalizar el primer ciclo de congelación (Figura 13).

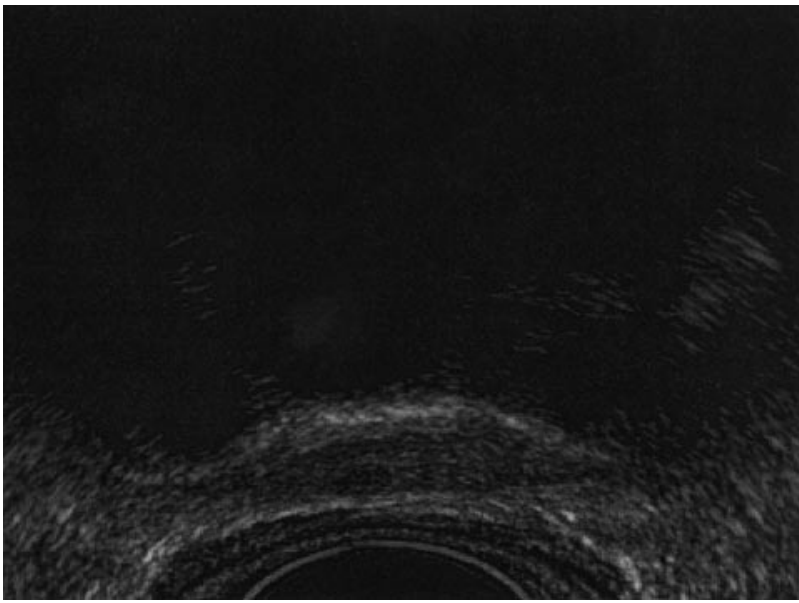

FIGURA 10. Sólo permanece intacta la zona posteromedial.

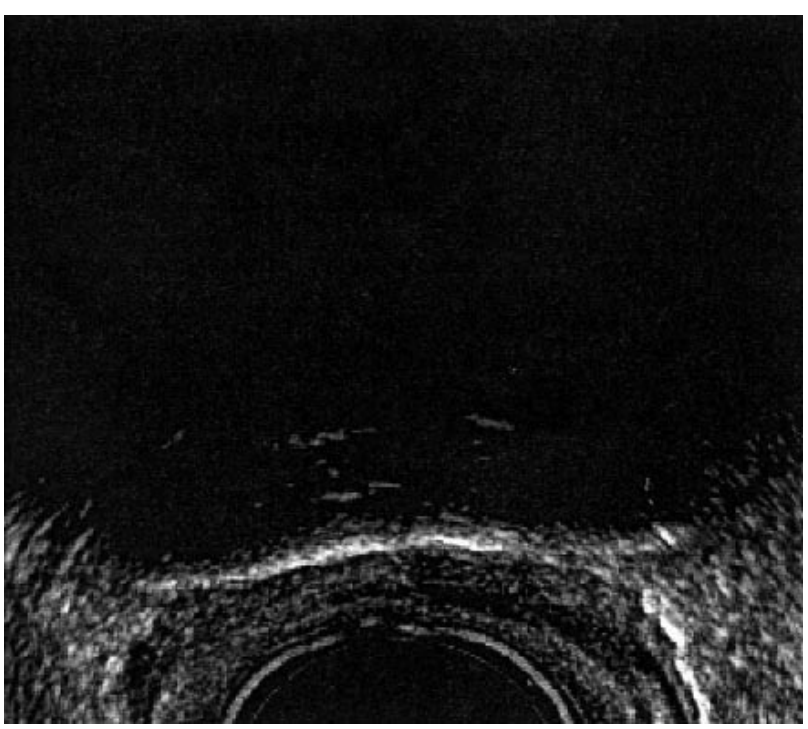

FIGURA 12. Sustitución total de la glándula por la bola helada.

Con la combinación de cortes transversal y longitudinal aseguramos que la pared rectal no se encuentra afectada por la bola de hielo (Figuras 14A y $14 \mathrm{~B}$ ), hemos alcanzado el límite y temperaturas deseadas y se finaliza el primer ciclo de enfriamiento. En las siguientes imágenes podemos apreciar como el límite de la bola helada se extiende hasta la serosa del recto, pero sin llegar más allá. Esto garantiza la integridad rectal y la ausencia de fístulas posteriores.

El procedimiento completo de la crioablación prostática consta de dos ciclos de congelación-calentamiento. El proceso del calentamiento es inverso al descrito. Ecográficamente no hay datos de interés durante toda esta fase excepto al final del ciclo. Con ecografía transrectal apreciamos la involución de la 

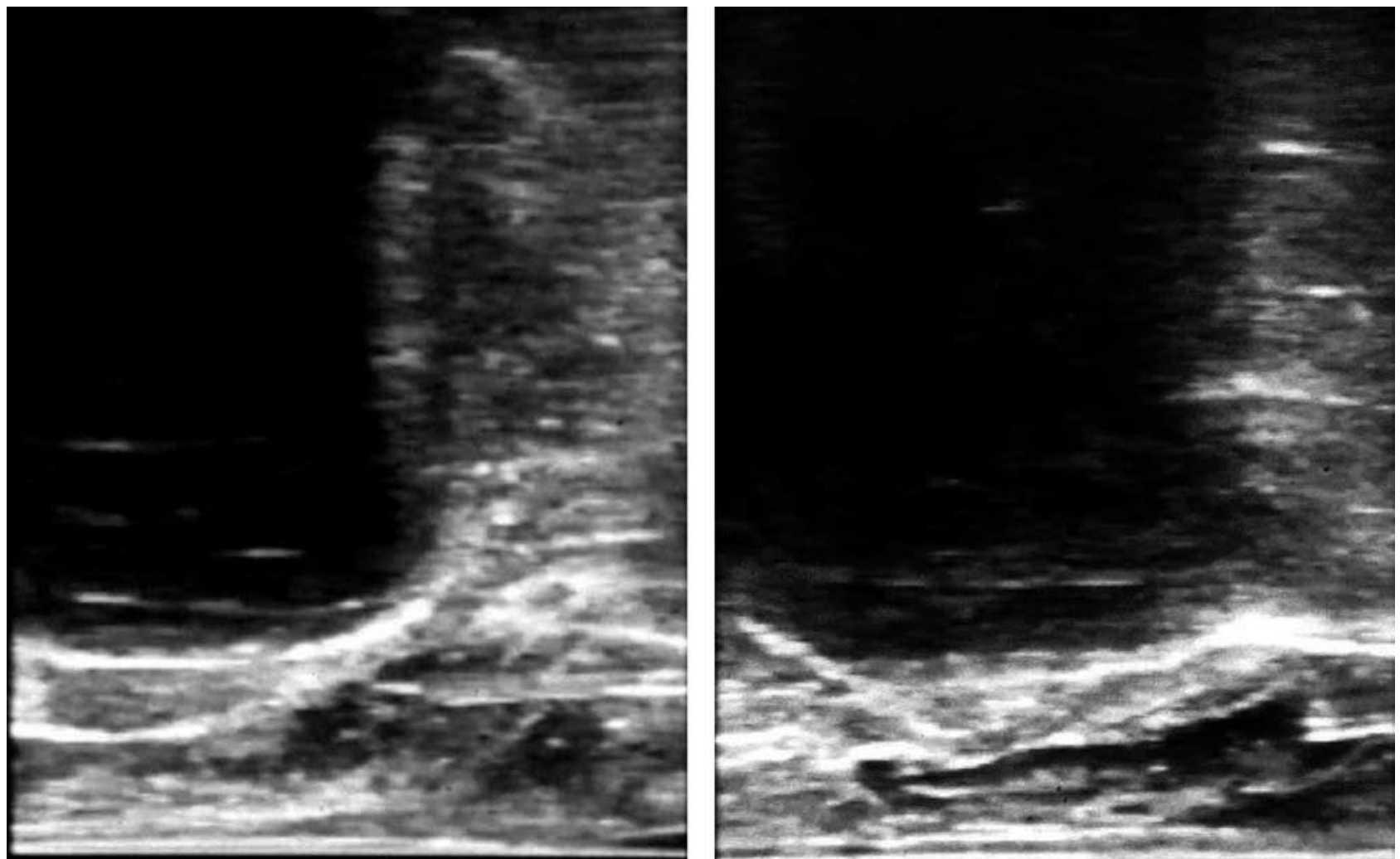

FIGURA 13. Reinyección de suero salino en el espacio próstato-rectal.

zona congelada y la desaparición total de la bola de hielo de forma progresiva (Figura 15).

Ahora la imagen ecográfica presenta algunas características especiales (Figura 16). Los lími-

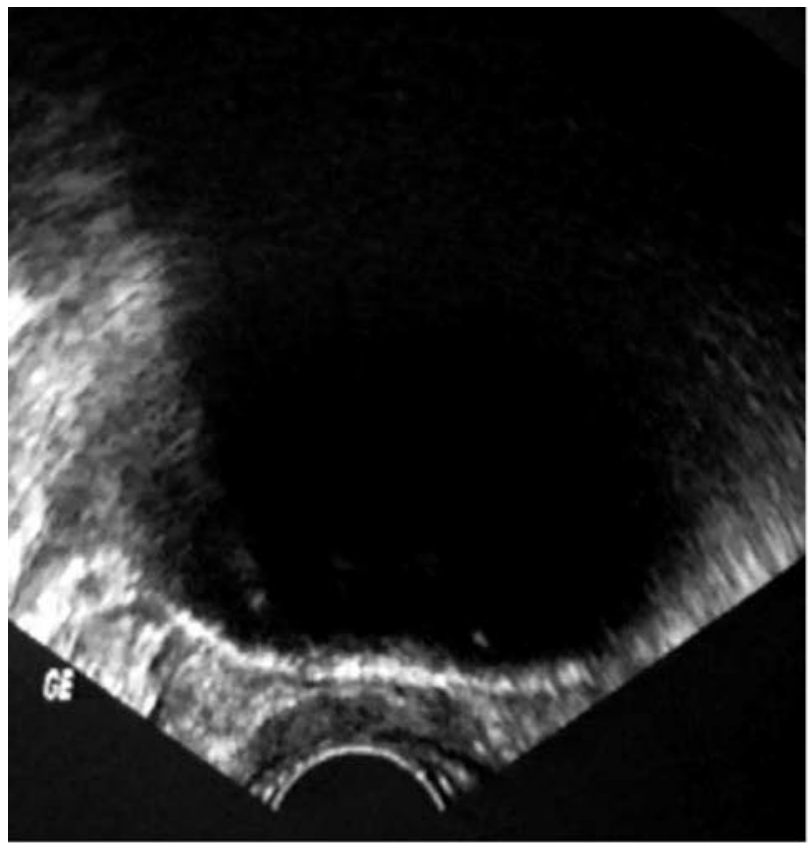

FIGURA 14A) Corte transversal final. tes anatómicos de la glándula vuelven a ser visibles pero de forma imprecisa y la ecoestructura prostática se vuelve heterogénea. Hay alternancia de zonas hiperecogénicas correspondientes a las criosondas y zonas hipoecóicas de tejido que permanece aún

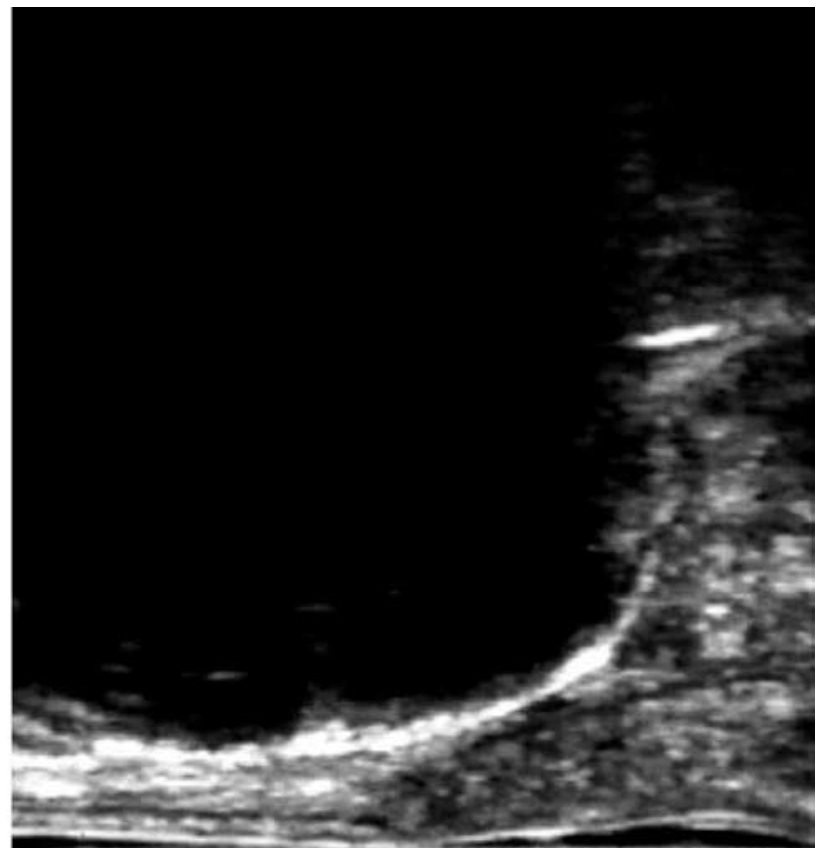

FIGURA 14B) Corte longitudinal final 


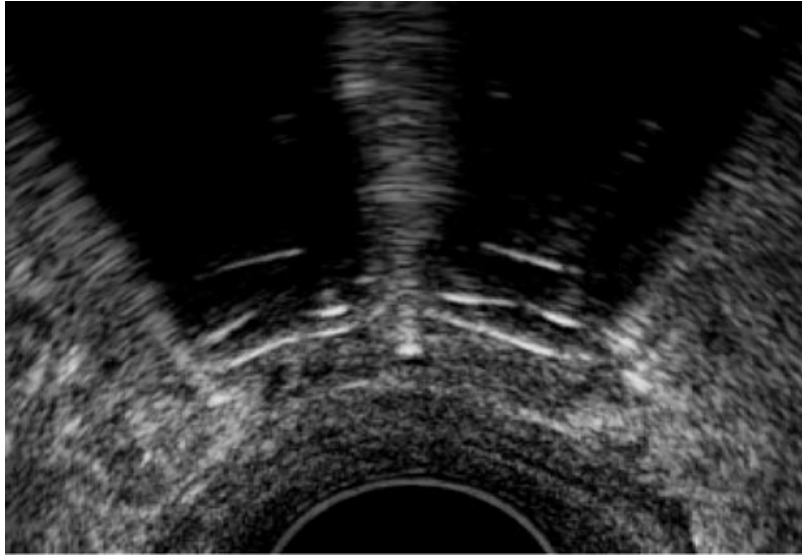

FIGURA 15. Involución de las bolas de hielo durante el calentamiento.

parcialmente congelado con sus refuerzos característicos. Igualmente podemos apreciar pequeñas áreas hemorrágicas próximas a las criosondas. En este momento del procedimiento el suero salino inyectado ha difundido por los tejidos y no es apreciable la separación artificial entre recto y glándula prostática.

En toda la revisión realizada nos hemos referido a la técnica que utilizamos en nuestro Servicio, el sistema coaxial de Endocare Cryo/44 de 2,4 mm de diámetro (8).

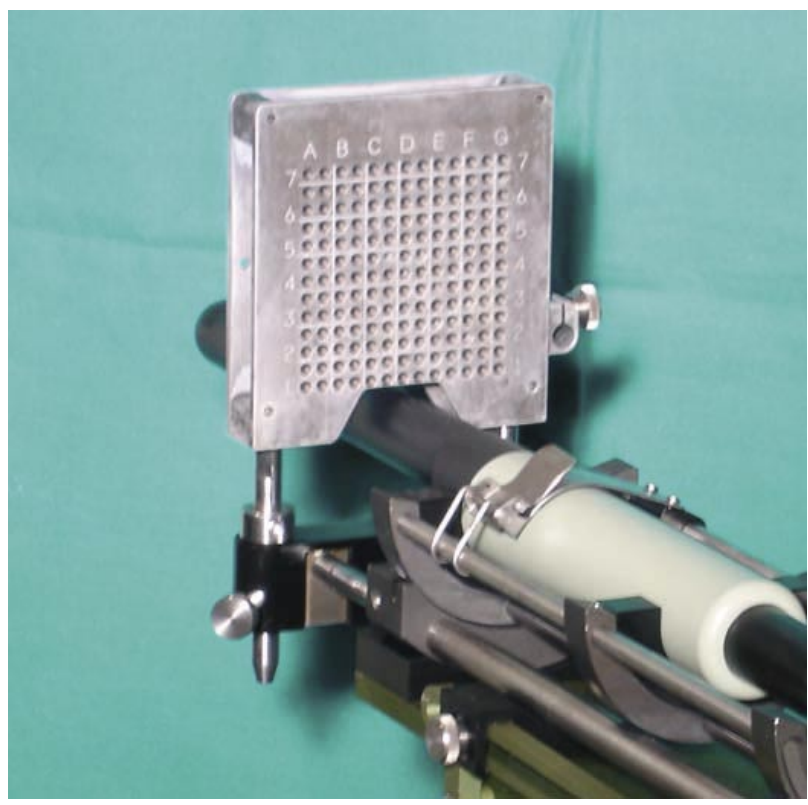

FIGURA 17. Sistema de gradilla adaptado para el sistema Galil.

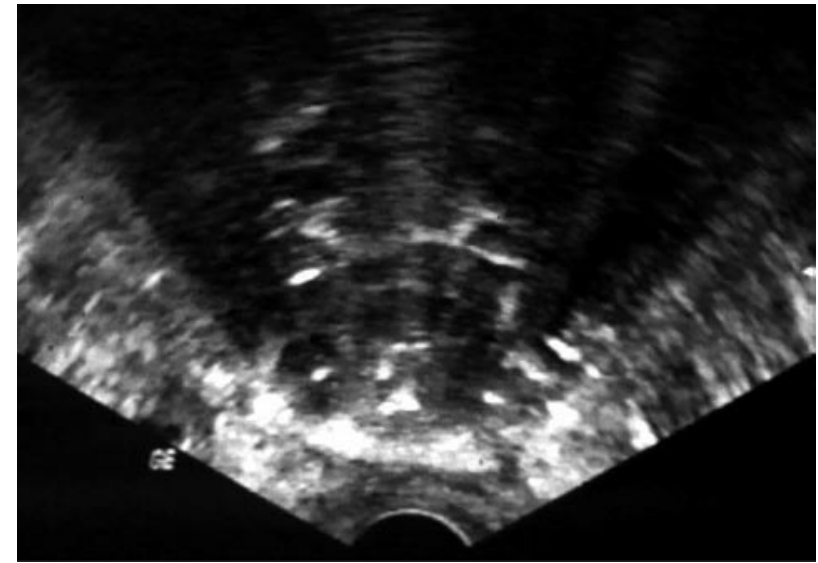

FIGURA 16. Imagen ecográfica al final del ciclo de calentamiento.

Existe otra técnica: el sistema Galil que utiliza agujas ultrafinas que originan una bola de hielo de aproximadamente $1 \mathrm{~cm}$. de diámetro. Su colocación se hace de forma más selectiva, en la zona periférica. Es necesaria la utilización de un sistema de gradilla fijo traducido al ecógrafo mediante el software adecuado y el apoyo de la ecografía transrectal para asegurar su colocación definitiva (Figura 17).

El número de agujas es muy superior, siendo necesarias entre 20 y 30, como afirma Saliken (13), para asegurar la congelación de la próstata.

Las imágenes obtenidas por ecografía transrectal son las mismas: zonas hipoecóicas circulares con refuerzo hiperecogénico. El control de crecimiento y control de la pared rectal no varía de una técnica a otra.

\section{¿Qué papel juega la ecografía transrectal en el segui- miento de los pacientes tratados con crioterapia?}

Los ciclos de congelación-calentamiento provocan daños tisulares a nivel glandular y estromal derivados de la necrosis y apoptosis celulares. La primera consecuencia es la disminución del volumen prostático que alcanza su mínimo entre los 3 y 6 meses posteriores al tratamiento, para estabilizarse, con un incremento ligero del tamaño de la glándula, alrededor del año de evolución. La segunda son los hallazgos anatomopatológicos observados (14): necrosis, zonas hemorrágicas más o menos evolucionadas, fibrosis, hialinización, microcalcificaciones, hiperplasia de células basales, metaplasia celular e incremento del número de capilares hemáticos. Todos estos cambios traducen, en consecuencia, alteraciones macroscópicas de la glándula prostática. 
La ecografía transrectal ve limitada su sensibilidad en el seguimiento de los pacientes sometidos a crioterapia prostática, excepción hecha de la determinación del volumen prostático (15). La próstata se presenta con límites definidos, algo irregulares y con una ecoestructura heterogénea, con zonas hiperecogénicas que traducen calcificaciones y procesos de cicatrización, y áreas hipoecóicas (Figuras 18 y 19). Estas zonas hipoecogénicas no tienen el mismo significado que las áreas nodulares de menor densidad observadas en una próstata no tratada y que se relacionan con la aparición del adenocarcinoma a ese nivel.

Evidentemente, y fuera de toda discusión, el control definitivo de los pacientes tratados se lleva a cabo mediante la realización de biopsia prostática sextante transrectal y ecodirigida. En nuestro Servicio la indicamos a los 6, 12 y 24 meses y posteriormente a los 5 años.

\section{BRAQUITERAPIA PROSTÁTICA}

La braquiterapia es una forma de radioterapia en la que las fuentes radiactivas se colocan temporal o permanentemente en el interior del volumen a irradiar, en el caso del cáncer de próstata en el interior de la glándula prostática.

El objetivo de esta técnica es administrar una dosis de radiación absorbida, suficiente para eliminar el tejido tumoral y respetar la uretra y los tejidos periprostáticos, para conseguir resultados semejantes a los de la prostatectomía con menos secuelas y complicaciones postratamiento.

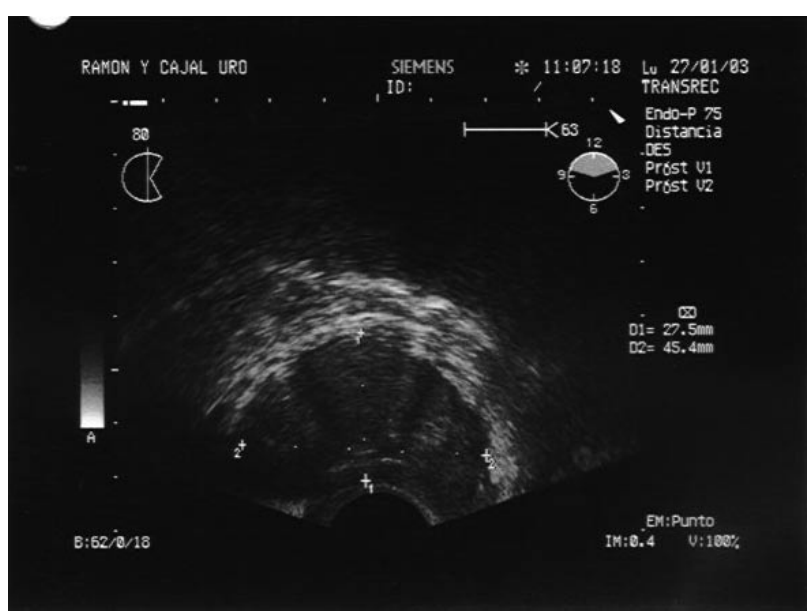

FIGURA 18. Control evolutivo a los 3 meses.
La implantación de los isótopos radiactivos se realiza mediante una agujas que son guiadas a través del periné con un sistema ecográfico transrectal. El implante con fuentes permanentes o con semillas, es un procedimiento mínimamente invasivo.

La braquiterapia en próstata fue utilizada por Pasteau en 1911 que colocaba una aguja de radium en el interior de la uretra consiguiendo respuestas, pero con complicaciones. Se han realizado implantes permanentes por vía laparotómica baja, a mano alzada, que permitieron estimar las dosis necesarias y las dosis de tolerancia.

En 1981, Holm en Dinamarca utilizó los implantes por vía perineal incorporando diferentes avances tecnológicos para mejorar el posicionamiento de las fuentes radiactivas como la ecografía y el "template" o rejilla perforada para guiar las agujas. Posteriormente Radge y Blasko desarrollaron y han popularizado esta técnica (16).

En la última década ha resurgido la braquiterapia prostática como consecuencia de la introducción de nuevos isótopos, técnicas de carga diferida, dosimetría computerizada, modernas técnicas de imagen, mejor conocimiento de la radiobiología y utilización de diferentes isótopos y tasas de dosis. La ecografía transrectal de próstata se vuelve de nuevo imprescindible para el total desarrollo de esta técnica.

Existen varias contraindicaciones para la indicación de la braquiterapia como modalidad única. No son objeto de análisis en esta revisión, pero sí debemos mencionar alguna de ellas por la relación

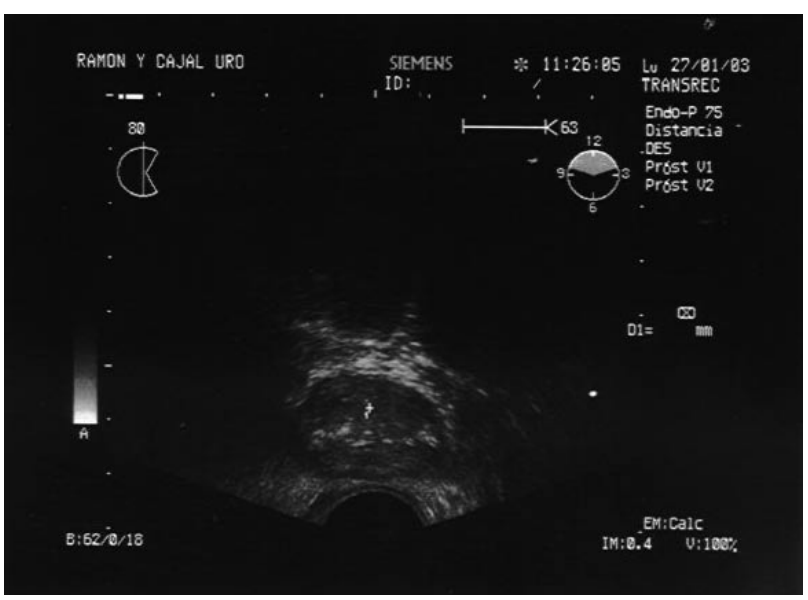

FIGURA 19. Evolución a los 6 meses. La glándula es de menor tamaño y la ecoestructura es más heterogénea. 
estrecha que mantienen con la ecografía transrectal. Son el volumen prostático mayor de $50 \mathrm{cc}$, la presencia de un lóbulo medio prostático prominente y la angulación de las ramas isquiopubianas que puede interferir con la colocación de las agujas.

La braquiterapia prostática precisa de un equipamiento especial derivada de la propia naturaleza de la técnica, al utilizar semillas radioactivas, la necesidad de un software para la planificación y la necesidad de un ecógrafo transrectal con software template para braquiterapia prostática (Figura 20).

Existen dos técnicas para la implantación permanente de los isótopos de yodo: la "técnica en dos tiempos" que han desarrollado Radge y Blasko que necesita una volumetría y planimetría ecográficas previas a la realización de la dosimetría clínica (16); y la "técnica en un tiempo", desarrollada por Stone y Stock, en que la colocación de las semillas se decide en el momento de acuerdo con la ecografía transrectal y la dosimetría es realizada en tiempo real.

La técnica recomendada por la ABS (American Brachytherapy Society) y por la ESTRO (European Society for Therapeutic Radiology and Oncology) es la "Técnica en dos tiempos". Este procedimiento es el que realizamos en nuestro Centro.

La ecografía transrectal juega un papel determinante en varias fases: el pre-planning y el implante.

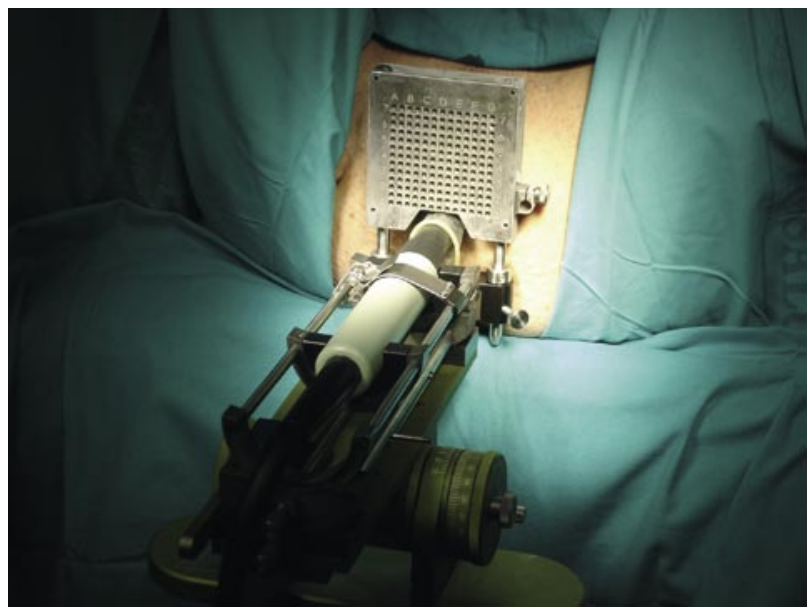

FIGURA 20. Ecógrafo transrectal con sistema fijo y gradilla para braquiterapia.

\section{Pre-planing}

Colocado el paciente en la posición necesaria (ver más adelante) el primer punto es determinar la posición del arco púbico y las posibles interferencias de las ramas isquiopubianas con el límite prostático para la colocación de las agujas portadoras de las semillas. Marcamos el refuerzo ecográfico óseo del pubis en su borde inferior y trasladamos la imagen hasta la próstata, localizando el corte transversal de mayor tamaño. Las marcas realizadas no deben interferir con el límite más anterior de la próstata (Figura 21).

El siguiente paso es el cálculo del volumen prostático, pero de una forma más exacta que la recomendada por Terris o Monseur, puesto que la dosis de radiación a recibir depende, de una forma muy estrecha, del volumen de la glándula. Se utiliza una aproximación matemática basada en cortes ecotomográficos de la próstata y el intervalo fijado entre los diferentes corte (17):

"V $=I \times(S 1+S 2+\ldots .+S n) "$ donde I es el intervalo.

El paciente se coloca en posición de litotomía y se realiza la volumetría de la próstata mediante ecografía transrectal. Esta prueba se realiza con anestesia intraraquídea o sedación para evitar que los movimientos del paciente puedan interferir en el cálculo final. Recordemos que el cálculo del volumen debe ser muy exacto. El transductor intrarectal se coloca sobre un sistema de posicionamiento calibrado de forma que quede absolutamente fijo. Este soporte

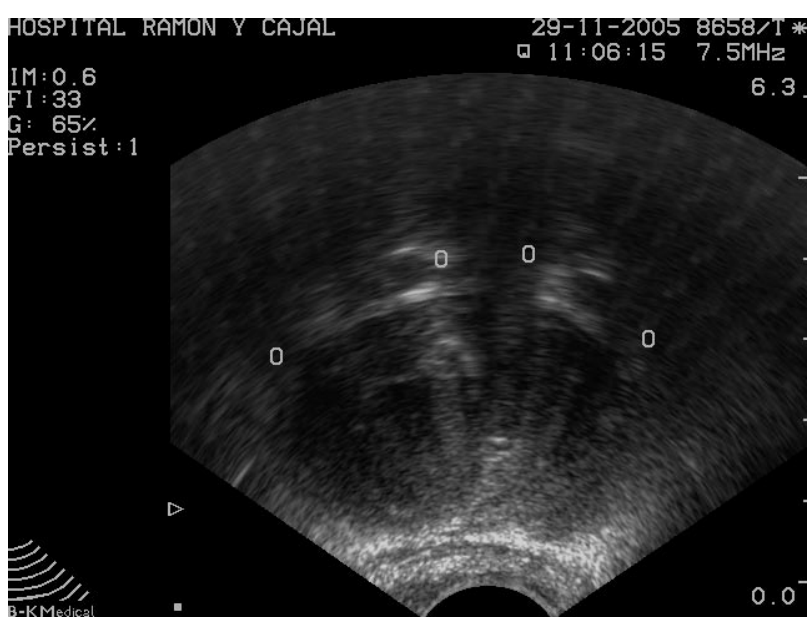

FIGURA 21. Obsérvese la distancia de seguridad entre la próstata y el hueso previamente reseñado con las marcas realizadas (0). 


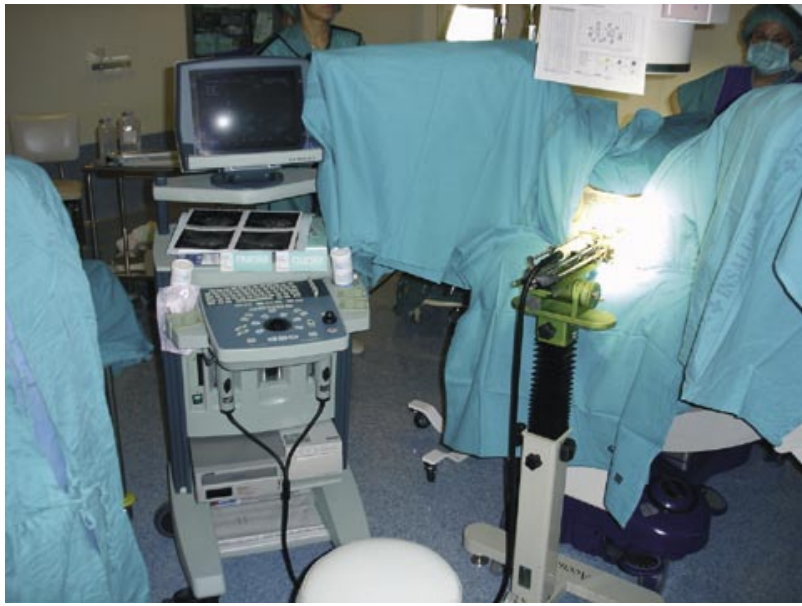

FIGURA 22. Posicionamiento y fijación del transductor rectal.

permite realizar secciones ecográficas transversales de la próstata cada $5 \mathrm{~mm}$, desde la base de la misma hasta el ápex (Figuras 20 y 22).

En cada una de las secciones se delimita el perímetro de la próstata. El ecógrafo lleva incorporado un software específico, que calcula automáticamente los volúmenes parciales, y el volumen total de la glándula. Las imágenes de la ecografía son transferidas al sistema de planificación para el cálculo de la dosis y ubicación de las semillas $(16,18)$.

El primer corte ecográfico válido se localiza a nivel de la base de la próstata y se denomina "corte 0 ", realizándose cortes transversales cada 5 $\mathrm{mm}$ hasta el ápex. Los cortes previo $(-0,5)$ y posterior

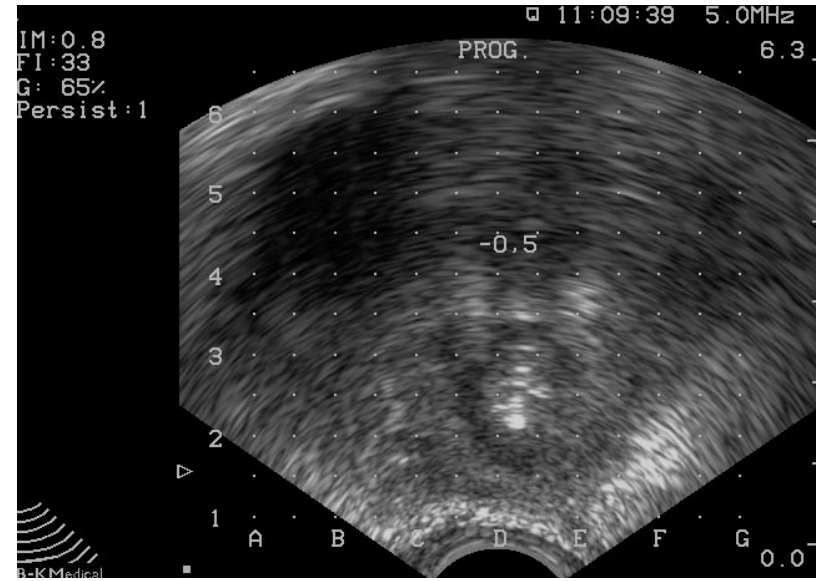

FIGURA 23. Corte "-0,5" localizado en cuello vesical. La imagen hiperecogénica central corresponde al globo y sonda vesical.

$(+0,5)$ no influyen en el cálculo volumétrico pero deben realizarse para constatar los límites y la ausencia de tejido prostático susceptible de tratamiento. En las siguientes imágenes representamos algunos de los cortes realizados en un estudio para el cálculo del volumen. Obsérvese como se refleja el área dibujada y el volumen alcanzado hasta ese momento (Figuras 23 a 26 ).

En todos estos cortes es fundamental reseñar la situación de la uretra para que el posicionamiento de las agujas con las semillas garantice una zona de seguridad que evite el daño radiactivo sobre la misma (19). Existe una maniobra que ayuda a localizar la uretra, intentando dejar algo de aire en el interior de la sonda al finalizar la repleción vesical con suero

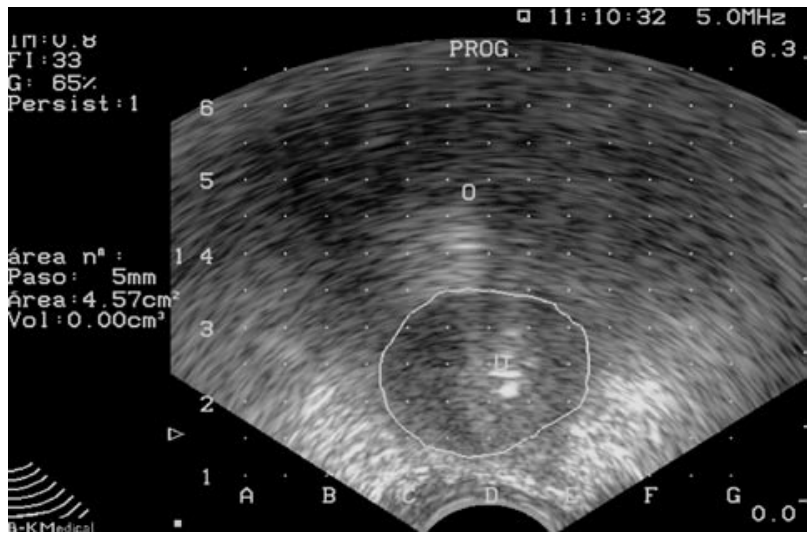

FIGURA 24. Primer corte en base de la próstata. Corte "O".

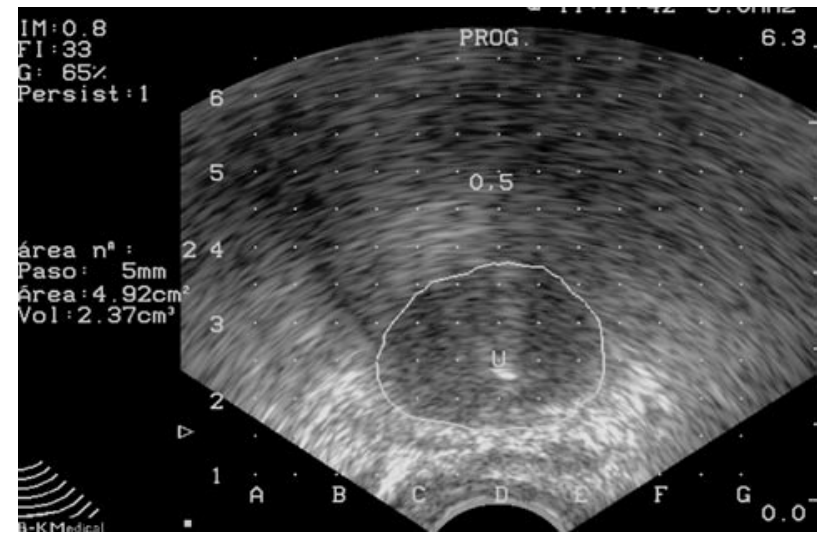

FIGURA 25. Corte siguiente "O,5". Obsérvese el cálculo del volumen. 


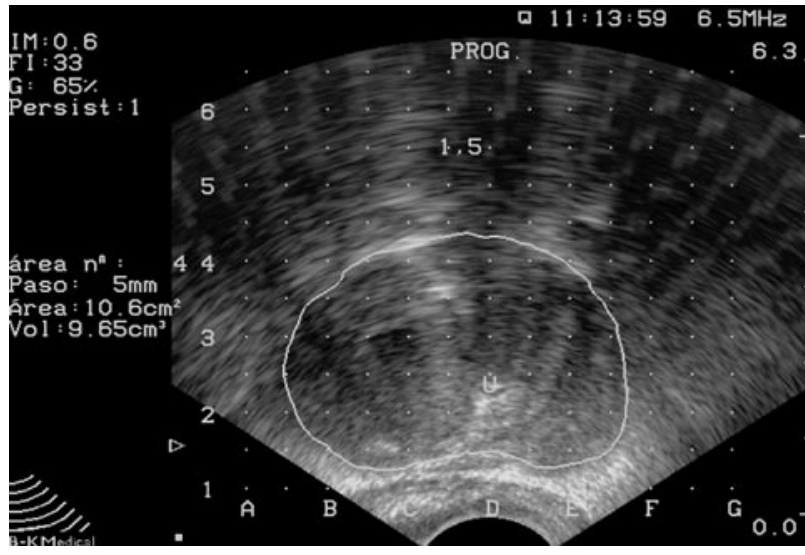

FIGURA 26. Corte "1,5". La marca "U" corresponde a la localización de la uretra.

fisiológico. Esto nos proporciona una imagen sonolúcida con refuerzo posterior o doble refuerzo que facilita la localización uretral.

En la Figura 27 representamos el último corte del estudio y se obtiene el cálculo exacto del volumen. El nivel siguiente sería el corte " $+0,5$ " realizado $5 \mathrm{~mm}$ más allá del pico prostático. Es un corte de referencia y no tiene valor en el cálculo volumétrico porque, a ese nivel, ya no existe tejido prostático.

\section{Implante}

Es realizado después de la volumetría, cuando se dispone de las semillas. Es fundamental la exacta reproducción de la posición de la próstata ya que la ubicación de las semillas decidida en la dosimetría

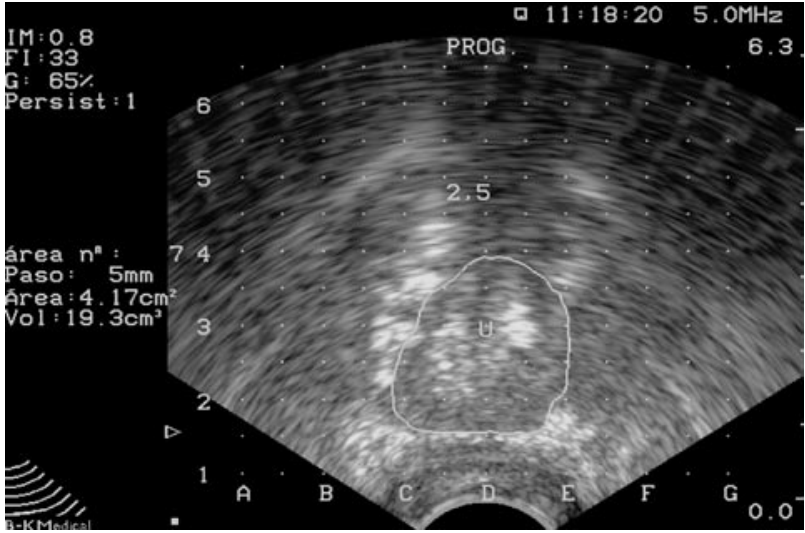

FIGURA 27. Último corte a nivel ápex. El volumen total es de 19,3 cc.

se ha realizado para esta posición. El implante se realiza, también, bajo anestesia intraraquídea y en posición de litotomía.

En este punto la ecografía transrectal vuelve a ser la base del procedimiento, basándonos en las imágenes obtenidas durante la fase anterior. Con el transductor transrectal se reproduce la ecografía prostática que se realizó el día de la volumetría.

La técnica del implante en "un solo tiempo" pretende eliminar esta dificultad decidiendo la colocación de las semillas en función de la ecografía transrectal y en tiempo real, considerando "in situ", las variaciones que sobre el volumen y los límites prostáticos provoca el trauma de la inyección de las agujas cargadas, amén de otras consideraciones que afectan exclusivamente al terreno radioterápico.

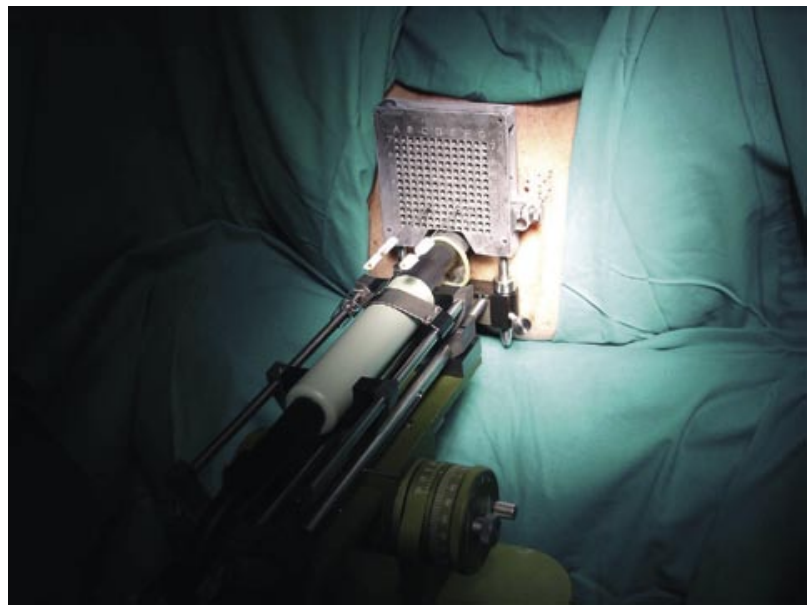

FIGURA 28. Colocación para el implante y fijación de la próstata.

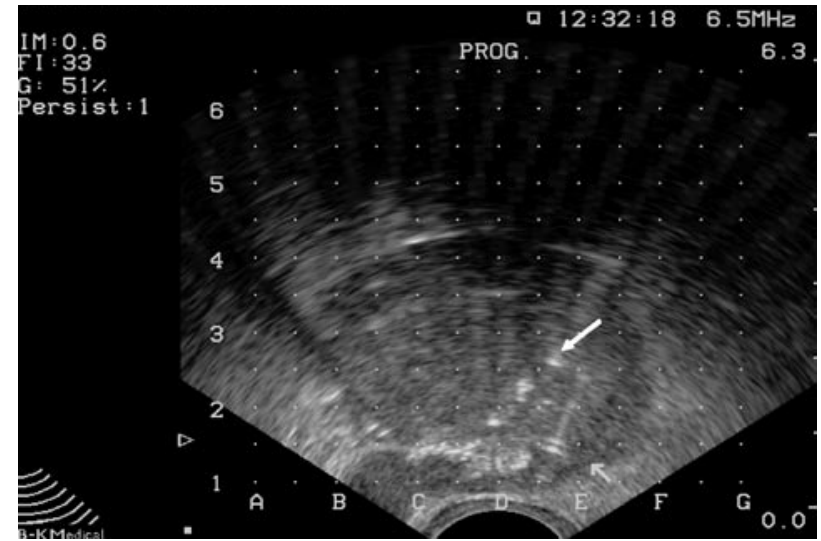

FIGURA 29. Flecha superior: semilla implantada. Flecha inferior: extremo de la aguja y su doble refuerzo. 


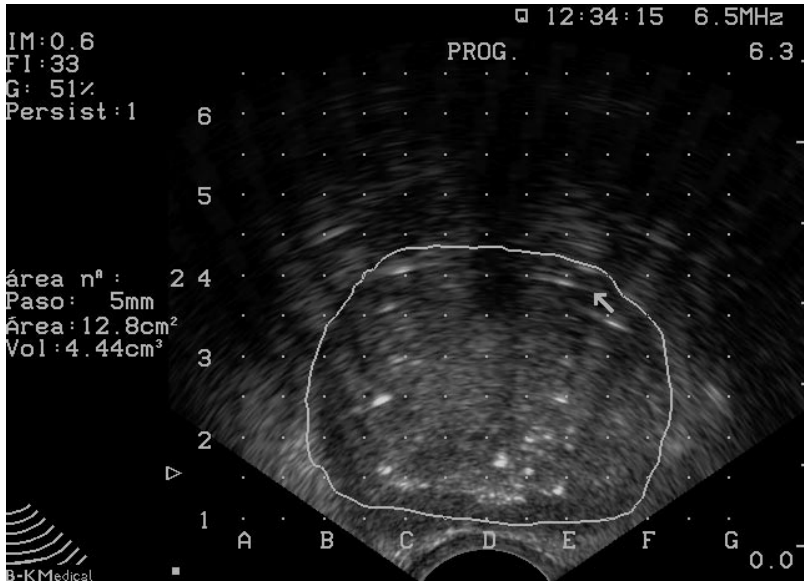

FIGURA 30. Semillas implantadas en la zona periférica. La flecha marca el doble contorno de una aguja recién colocada.

Una vez situada la glándula prostática en el lugar adecuado se coloca una rejilla multiperforada (template) sobre el periné, a través de la cual se irán ubicando las semillas en las coordenadas preestablecidas. Si se va a realizar el implante con agujas precargadas inicialmente hay que estabilizar la posición de la próstata mediante 2 ○ 3 agujas de estabilización (Figura 28).

Siguiendo las indicaciones de la volumetríadosimetría procedemos a insertar las agujas con las semillas en su interior. La técnica se hace bajo control ecográfico en corte transversal. La imagen que se aprecia es una señal hiperecogénica, brillante y de doble refuerzo cuando se localiza el extremo más distal de la aguja, lo que nos orienta a la hora de situarla en su lugar y plano exactos (p. ej. corte "1,5"). La imagen de la semilla depositada es hiperecogénica pero con refuerzo único (Figura 29).

Se sabe que la localización del adenocarcinoma de próstata es periférica y multicéntrica. La mayoría de las agujas deben colocarse en esta zona prostática para asegurar que el límite más externo de la glándula este incluido dentro de la curva de isodosis del radionúclido.

En la Figura 30 podemos apreciar la colocación de la aguja. Obsérvese que la mayoría de las semillas implantadas hasta el momento tienen una distribución en la zona más periférica de la glándula. El dibujo del límite prostático es didáctico y realizado para resaltar lo que acabamos de referir. No es necesario realizar este dibujo durante la realización del implante.

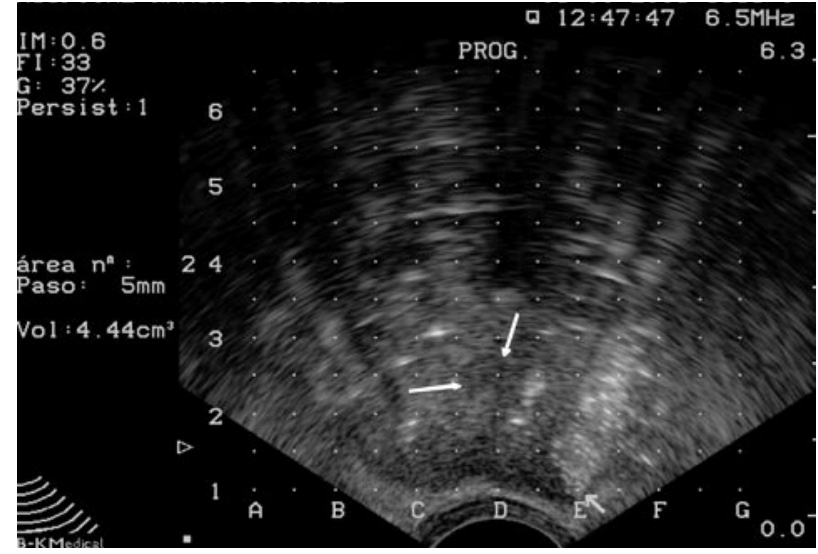

FIGURA 31 . Semillas implantadas en la zona periférica. La flecha marca el doble contorno de una aguja recién colocada.

El número de semillas cargadas en cada aguja es variable y viene determinado por la dosimetría. La separación de cada semilla dentro de la aguja es de $5 \mathrm{~mm}$. Esto permite cubrir la totalidad de la longitud de la próstata y asegurar que toda la glándula se encuentra bajo los efectos del radionúclido. Por tanto la densidad de semillas en cada corte es variable.

El procedimiento finaliza una vez implantadas todas las agujas. En la Figura 31 podemos observar, en un corte transversal aleatorio, la disposición de las semillas cubriendo prácticamente la totalidad de la próstata, respetando la uretra y tejidos periuretrales y concentrando la mayor densidad en la zona periférica.

\section{Control post-tratamiento}

El control posterior de los pacientes tratados con braquiterapia prostática se realiza con TAC (20). La ecografía no tiene un claro papel en el seguimiento de estos pacientes, excepción hecha de la necesidad de realizar una biopsia si las determinaciones analíticas de PSA hacen sospechar el fracaso de la braquiterapia y la persistencia del tumor.

\section{BIBLIOGRAFÍA y LECTURAS RECOMENDADAS (*lectura de interés $y^{* *}$ lectura fundamental)}

*1. TERRIS, M.K.; STAMEY, T.A.: "Determination of prostate volumen by transrectal ultrasound". J. Urol., 145: 984, 1991. 
*2. MONSEUR, J.; MALHERBE, F.: "Calcul du volumen prostatique par échografie endorectale". J. Urol., 98: 78, 1992.

*3. GONDER, M.J.; SOANES, W.A.; SMITH, V.: "Experimental prostate cryosurgery". Invest. Urol., 1: 610, 1964.

*4. GONDER, M.J.; SOANES, W.A.; SHULMAN, S.: "Cryosurgical treatment of the prostate". Invest. Urol., 3: 372, 1966.

*5. FLOCKS, R.H.; NELSON, C.M.; BOATMAN, D.L.: "Perineal cryosurgery for prostatic carcinoma”. J. Urol., 108: 933, 1972.

*6. ONIK, G.; PORTERFIELD, B.; RUBINSKY, B. y cols.: "Percutaneous transperineal prostate cryosurgery using transrectal ultrasound guidance: animal model". Urology, 37: 277, 1991.

**7. ONIK, G.; COHEN, J.K.; REYES, G.D. y cols.: "Transrectal ultrasound-guided percutaneous radical cryosurgical ablation of the prostate". Cancer, 72: 1291, 1993.

**8. WONG, W.S.; CHINN, D.O.; CHINN, M. y cols.: "Cryosurgery as a treatment for prostate carcinoma”. American Cancer Society, 79: 963, 1997.

**9. ESCUDERO BARRILERO, A.; RODRIGUEZPATRON, R.; ARIAS FUNEZ, F.: "Principios técnicos de la criocirugía prostática”. Arch. Esp. Urol., 56: 1089, 2003

*10. CHIN, J.L.; DOWNEY, D.B.; MULLIGAN, M. y cols.: "Three-dimensional transrectal ultrasound guided cryoablation for localized prostate cancer in nonsurgical candidates: a feasibility study and report of earlier results". J. Urol., 59: 910, 1988.

*11. WOJTOWICZ, A.; SELMAN, S.; JANKUN, J.: "Computer simulation of prostate cryoablationfast and accurate approximation of the exact solution”. Computed Aided Surg., 2: 135, 2003.
**12. ONIK, G.:"Image-guided prostate cryosurgery: state of the art". Cancer Control, 8: 522, 2001.

*13. SALIKEN, J.C.; DONNELLY, B.J.; REWCASTLE, J.C.: "The evolution and state of modern technology for prostate cryosurgey". Urology, 60: 26, 2002.

**14. ESCUDERO BARRILERO, A.; ARIAS FUNEZ, F.; RODRIGUEZ-PATRON RODRIGUEZ, R. y cols.: "Criobiología y lesiones anatomopatológicas inducidas por la congelación-deshielo en el tejido prostático. $2^{\text {a }}$ parte". Arch. Esp. Urol., 57: 1073, 2004.

**15. GALOSI, A.B.; MUZZONIGRO, G.; POLITO, M. Jr. y cols.: "Role of transrectal ultrasonography in the follow-up of patients treated with prostatic cryosurgery". Arch. Ital. Urol. Androl., 72: 276, 2000.

**16. BLASKO, J.; GRIMM, P.D.; RADGE, H.: "Brachytherapy and organ preservation in the management of carcinoma prostate". Seminar. Radiat. Oncol., 3: 240, 1993.

*17. DANA, A.: "Atlas de Ecografía de la Próstata" Edit. Masson S.A., 3: 16, 1994.

*18. ANDERSON, L.L.: "Plan optimization and dose evaluation in brachytherapy". Seminar. Radiat. Oncol., 3: 290, 1993.

*19. WALLNER, K.; ROY, J.; HARRISON, L.: "Dosimetry guidelines to minimize urethral and rectal morbidity following transperineal $\mathrm{I}-1^{\circ} 25$ prostate brachytherapy". Int. J. Radiat.Oncol. Biol. Phys., 32: 465, 1995.

**20. WALLNER, K.; CHIU-TSOA, S.T.; ROY, J. y cols.: "An improved method for computerized tomography planned transperineal 125 iodine prostate implants". J. Urol., 146: 90, 1991. 